\title{
ADVERTISING PAY PER CLICK (PPC) DENGAN GOOGLE ADSENSE PERSPEKTIF HUKUM ISLAM
}

\author{
Dika Saputri \\ email : dikasaputri465@gmail.com
}

\begin{abstract}
The internet as an effective medium in the world of business (especially in the field of marketing) from the viewpoint of the bisins to market the products produced. Various models of product offerings are conceptualized by business people issued to capture market segments. Pay per Click (PPC) is one of several programs on the internet that has the concept of giving gifts to internet users when opening advertisements submitted by advertising companies through certain sites. One dollar producer from the internet is Google Adsense. Google Adsense is a dollar-producing affiliate program issued by Google Search Engine companies by collaborating with web or blog owners in terms of Advertising. With this kind of affiliate business model, publishers (web owners or blogs) will get dollars from advertisements displayed on the web or blog. Ads displayed on the web or blog can be text or images. There are many titles for revenue generated from Google Adsense. And to find out whether or not the Muslim community is capable of following a business in the field of Advertising, such as Pay Per Click (PPC), there needs to be a study that discusses the business of Islamic Law.
\end{abstract}

Keywords: Pay per click, Google Adsense, Islamic Law

\section{Pendahuluan}

Dewasa ini, teknologi semakin canggih pada tiap-tiap bidang kehidupan manusia, segala kebutuhan dan kegiatan manusia akan semakin mudah dengan adanya perkembangan dan kemajuan teknologi. Melalui teknologi, apa yang dulunya tidak mungkin, kini menjadi mungkin. Salah satu perkembangan teknologi dalam bidang informasi dan telekomunikasi adalah ditandai dengan hadirnya Internet (Dwi Suwiknyo, 2009:1). Kehidupan masyarakat modern saat ini sudah pasti membutuhkan internet, baik itu untuk bekerja, belajar, maupun bersosialisasi dengan teman ataupun orang-orang yang baru dikenal. Kebanyakan orang mengakses internet hanya untuk mencari informasi. Padahal sebenarnya internet memiliki fungsi lain yang menguntungkan bagi pengguna internet, misalnya dengan berbisnis melalui internet (Hurriyah Badriyah, 2014:7). 
Salah satu contoh bisnis internet yang gratis adalah program affiliasi pada Google Adsense. Program ini merupakan program advertising yang dilakukan oleh google yang bekerjasama dengan pemilik web atau blog dimana iklan dari Google dapat ditampilkan dalam bentuk banner. Didalam program ini seseorang yang teraffiliasi dengan Google didalam program Google Adsense dapat berpenghasilan dengan gaji dollar sesuai standar yang ditetapkan oleh Google. Google Adsense adalah program affiliasi untuk bisnis internet yang sangat populer di dunia online saat ini. Semua orang bisa berpartisipasi menjadi pengiklan bagi Google dengan syarat mudah dan cepat, cukup dengan menempatkan iklan-iklan Google di situs mereka. Dengan metode komisi Pay Per Click (PPC).

Google memberikan metode penghasilan uang jauh lebih sederhana dan sangat mudah. Berbeda dengan affiliasi lainnya, yang mengharuskan publisher menjual sesuatu baru mendapat komisi. Google Adsense telah membawa revolusi baru dalam bisnis internet, program ini telah menghasilkan jutawan online tanpa harus mencari investor-investor besar seperti yang biasa dilakukan perusahaanperusahaan dot com. Adakalanya pemilik situs web atau blog mendapatkan keuntungan dari setiap 1000 impression atau tampil (Paid Per Impression), akan tetapi metode ini hanya berlaku untuk iklaniklan tertentu dan dibuka di negara tertentu pula. (Team Cyber, 2009:59) Pada dasarnya, program PPC merupakan sebuah cara bagi perusahaan untuk meningkatkan jumlah pengunjung ke website mereka. Hal ini dilakukan sebagai salah satu bentuk promosi terhadap produk atau jasa yang mereka tawarkan. Namun, pada perkembangannya program PPC tidak hanya bersifat promosi terhadap produk atau jasa, tetapi juga menawarkan seseorang untuk mendapatkan penghasilan tambahan dengan cepat dan mudah (Hurriyah Badriyah, 2014:22).

PPC merupakan program affiliasi yang akan membayar seseorang apabila meng klik iklan dari situs PPC. Setiap klik nilainya bervariasi ada yang $\$ 0.01$ per klik sampai $\$ 0.025$ per klik, tapi pada umumnya nilai rata-rata per klik yang diberikan sebesar $\$ 0.01$. Untuk free member iklan yang tampil cenderung sedikit, sekitar 10-16 iklan saja perhari. Artinya jika nilai per klik adalah $\$ 0,01$ maka hasil yang diperoleh dalam satu hari adalah $\$ 0.10-\$ 0.16$. Bagi seseorang yang sudah melakukan upgrade status membership dari free member menjadi bronze member atau gold member dengan membayar $\$ 0.20$ $\$ 100$ iklan yang muncul bisa ratusan perhari. Artinya jika nilai per klik adalah \$0.01 dikalikan 100 iklan, maka hasil yang diperoleh adalah $\$ 1$ (Hurriyah Badriyah, 2014:32). 


\section{Advertising Pay Per Click (PPC) Dengan Google Adsense}

Dengan perhitungan diatas apabila seseorang mengikuti status ini dengan free member maka total penghasilan yang ia peroleh selama sebulan ialah sebesar $\$ 3-\$ 4.8$, sedangkan bagi premium member, jumlah penghasilan yang diperoleh dalam sebulan adalah $\$ 30$. Akan tetapi pada prakteknya iklan yang dapat di klik dalam web tersebut, tidak setiap hari ada, artinya ketika seseorang telah melakukan klik iklan dalam satu hari, maka iklan untuk di klik akan ada lagi dalam jangka waktu dua sampai tiga hari.

Dalam transaksi muamalat, akad merupakan sebuah syarat yang wajib dilakukan oleh pihak yang bertransaksi, baik berupa transaksi jual beli, sewa menyewa, dan sebagainya. PPC merupakan salah satu dari beberapa jenis transaksi yang menggunakan jasa internet sebagai mediannya. Dalam hal ini tetap memerlukan sebuah akad, agar setiap transaksi yang terjadi sah menurut aturan fikih muamalat dalam Islam. Ada banyak kekurangan-kekurangan yang terjadi pada bisnis ini juga tentang status hukum dari uang yang belum begitu jelas. Berdasarkan permasalahan tersebut, penyusun ingin menganalisa status uang yang dihasilkan dari sistem advertising PPC dengan Google Adsense ini sesuai dengan hukum Islam.

\section{Mengenal Google Adsense}

Google adalah sebuah perusahaan penyedia layanan iklan online dan mesin pencari yang berbasis di mountain view, Kalifornia, Amerika Serikat. Awalnya Google dikembangkan oleh dua orang yang bernama Larry Page dan Sergey Brin. Tahun 1996 mereka masih menjadi mahasiswa di Universitas Stanford dan domain yang digunakan adalah Google.stanford.edu. Domain Google.com diregistrasikan pada 15 September 1997 dan perusahaan ini berdiri dengan nama Google Inc. Pada 7 September 1998 disebuah garasi rumah di Menlo Park, Kalifornia. Investasi awal yang diperoleh oleh perusahaan baru ini bernilai hampir \$1.1 juta, termasuk sebuah cek senilai \$100.000 dari Andy Bechtolsheim, salah seorang pendiri Sun Microsystems. (Vilency, 2010:2)

Program yang menghasilkan uang adalah google adsense. Program ini adalah program legal yang dibuat oleh google yang telah memiliki nama besar di dunia maya sebagai situs pencari yang terkenal. Google ini semacam makelar yang menghubungkan antara situs yang ingin mempromosikan web atau situsnya dengan pemilik web untuk ditumpangi iklan mereka yang sedang promosi. Disatu sisi google mendapatkan uang dari para pemilik web atau situs yang berpromosi lewat google yang dikenal dengan program google adword. Kemudian, google membayarkan uang tersebut kepada penyedia web atau situs 
yang ditumpangi oleh iklan dari google jika iklan yang dipasang oleh google tersebut diklik oleh orang lain. Program ini disebut program google adsense. Statistiknya seperti dibawah ini.

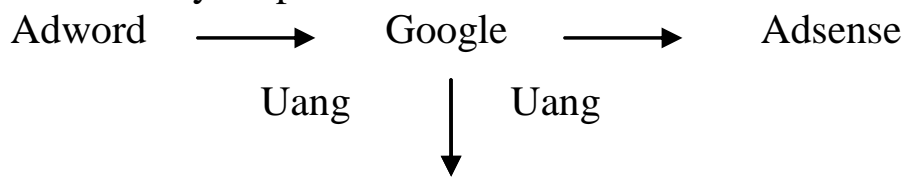

Mendapatkan Rabat

Google adsense merupakan sebuah program kerjasama periklanan yang menggunakan media internet, program ini diselenggarakan oleh google. Melalui program periklanan adsense, sebagai pemilik situs web, blog, yang telah mendaftar dan di setujui keanggotaanya bisa memasang unit iklan yang bentuk maupun materinya telah ditentukan oleh google pada halaman web. Para pemilik situs web atau blog tersebut akan mendapatkan pemasukan yang berupa pembagian keuntungan dari google bagi setiap iklan yang di klik oleh para pengunjung situs, sistem ini dikenal sebagai sistem Pay Per Click (PPC) atau bayar per klik (Hurriyah Badriyah, 2014:87).

Meskipun program adsense akan memberikan keuntungan besar, google telah menetapkan aturan ketat untuk melindungi kepentingan semua pihak yang terlibat di dalamnya, termasuk kepada pemasang iklan yang sering dirugikan oleh tindakan tidak terpuji pemilik situs anggota program adsense. (Team Cyber, 2009:63).

Potensi keuntungan mengikuti program adsense membuat banyak pemilik situs web mengembangkan berbagai metode untuk meningkatkan jumlah klik pada iklan yang ditayangkan. Sebagian metode terbukti ilegal dan melawan kebijakan resmi program adsense.

1. Istilah-istilah dalam google adsense

a. Publisher adalah orang atau pemilik situs yang sudah bergabung dan memasang iklan Adsense di situs mereka

b. Ad Units adalah iklan Adsense itu sendiri

c. Link Units hampir sama dengan ad units tetapi formatnya mirip dengan menu yang bisa kita temui di situs-situs web. Pembeda link units dengan ad units adalah pada saat pengunjung mengklik iklan ini. Pada link units ia akan diarahkan pada halaman hasil pencarian di search engine google. Publisher baru akan mendapatkan pemasukan apabila pengunjung mengklik salah satu ad units yang ada di halaman tersebut. Link units menghasilkan pemasukan uang lebih banyak dibandingkan dengan ad units biasa. 


\section{Advertising Pay Per Click (PPC) Dengan Google Adsense}

d. Adsense for content adalah iklan adsense yang dipasang di dalam suatu halaman. Iklan-iklan yang muncul berhubungan dengan isi halaman tersebut (kontekstual). Ad units dan link units termasuk ke dalam adsense for content.

e. Alternate ads adalah iklan yang muncul ketika iklan utama yang kontekstual dengan isi web habis. Google memperbolehkan kita untuk memasang alternate ads atau iklan alternatif. Jika ad units yang dibuat telah diatur dengan menggunakan alternate $a d s$ tidak muncul akan keluar iklan alternatif yang telah diatur sebelumnya.

f. Channel adalah semacam label yang dapat diberikan pada ads units, link units, adsense for search, dan referrals. Satu unit iklan dapat memiliki lebih dari satu label. Sebaliknya, satu label dapat digunakan untuk adsense akan dikelompokkan berdasarkan channels, sehingga memudahkan publisher untuk menganalisa performa adsense mereka. Umumnya publisher akan memberikan channels yang sama pada unit-unit iklan yang ada di satu situs. Jika ingin lebih details, diberikan nama channels yang berbeda pada setiap units iklan di masing-masing situs. Maksimal jumlah channels yang diperbolehkan adalah 200 kanal.

2. Kebijakan program adsense

Meskipun program adsense akan memberikan keuntungan yang besar, google telah menetapkan aturan ketat untuk melindungi kepentingan semua pihak yang terlibat didalamnya. Termasuk kepada pemasang iklan yang sering dirugikan oleh tindakan tidak terpuji olrh pemilik situs anggota program adsense. Beberapa larangan google yang harus ditaati pemilik situs web atau blog peserta program adsense, diantaranya sebagai berikut :

a) Meng klik iklan yang ditampilkan pada situs milik sendiri, baik secara manual ataupun dengan bantuan perangkat lunak khusus.

b) Dengan sengaja mendorong para pengunjung situs untuk mengklik iklan yang ditampilkan, misalnya dengan kata-kata "klik iklan ini" atau "kunjungi halaman ini"

c) Membuat pranala langsung menuju halaman hasil pencarian adsense untuk pencarian.

d) Mengisis secara otomatis kotak pencarian adsense dengan kata kunci tertentu.

e) Memanipulasi target iklan dengan kata kunci tersembunyi atau dengan inframe. 
f) Kode unit iklan adsense harus ditempatkan langsung pada kode html situs web tanpa adanya perubahan. Pemilik situs tidak diperbolehkan mengubah kode adsense dengan alasan apapun. Misalnya, dengan menampilkan hasil klik di jendela pop up atau mengalihkan target iklan. (Huriyah Badriah, 2014:89)

3. Optimasi penghasilan adsense

Potensi keuntungan yang mengikuti program adsense menjadikan banyak pemilik situs web mengembangkan berbagai metode yang mereka lakukanpun terbukti ilegal dan melawan kebijakan resmi program google adsense. Metode lain yang diperbolehkan, bahkan didorong penggunaanya oleh google, adalah sebagai berikut :

a) Modifikasi warna units iklan menggunakan pallet warna yang disediakan oleh adsense

b) Meletakan unit iklan pada posisi tertentu pada halaman web yang dianggap memiliki tingkat keterbacaan yang tinggi.

c) Menghilangkan garis yang ada pada tepi units iklan dan menyamakan warna latarnya dengan warna halaman web sehingga units iklan tersebut seperti membaur dengan isi halaman.

4. Sistem Keamanan dalam E-commerce

Faktor keamanan merupakan salah satu faktor yang sangat penting dalam sistem financial, baik dari sisi sistem tradisional ataupun sistem transaksi elektronik berbasis komputer. Dalam sistem tradisional, tekanan kita adalah pada pengelolaan dan penjagaan keamanan secara fisik. Sementara dalam perdagangan elektronik, hal ini itu harus ditambahi dengan penambahan perangkat-perangkat elektronik (perangkat lunak ataupun perangkat keras) untuk melindungi data,sarana komunikasi, serta transaksi.(Adi Nugroho, 2008:95)

Sistem keamanan dalam dunia komputer mulai terjadi perhatian serius para peneliti dan praktisi teknologi informasi sejak ditemukanya teknologi jaringan komputer. Pemicu berkembangnya isu di bidang ini adalah karena adanya fenomena pengiriman data melalui media transmisi (darat, laut dan udara) yang mudah dicuri oleh mereka yang tidak berhak. Data mentah dari sebuah komputer yang dikirimkan ke komputer lain pada dasarnya rawan terhadap "intervensi" pihak ketiga, sehingga diperlukan suatu strategi khusus agar terjadi, paling tidak ada dua hal: (Richardus Eko Indrajit, 2001:125) 


\section{Advertising Pay Per Click (PPC) Dengan Google Adsense}

1. Data yang di kirimkan tidak secara "fisik" agar tidak diambil oleh pihak lain yang tidak berhak; atau

2. Data yang dikirimkan dapat "diambil secara fisik" namun yang bersangkutan tidak dapat membacanya. Information security merupakan bagian yang sangat penting dari sistem $e$ - commerce.

Tingkat keamanan informasi yang dapat diterima di dalam e-commerce muthlak dibutuhkan.di era internet, semua kebutuhan dan keingian sedapat mungkin diterima dengan cepat, mudah dan aman. Untuk itulah peranan teknologi keamanan informasi benar-benar dibutuhkan. Diantara sistem keamanannya adalah sebagai berikut: pertama, Kriptografi (Cryptography). Kriptografi adalah ilmu yang mempelajari bagaimana membuat suatu pesan yang dikirim oleh pengirim dapat disampaikan kepada penerima dengan aman. (Riyeke Ustadiyanto, 2001:91) Kriteria aman dalam teknik kriptografi masih relatif. Minimal dalam teknik kriptografi dapat ditemukan empat kriteria aman, yaitu:

a) Confidentiality (kerahasiaan), artinya suatu pesan tidak boleh dibaca atau diketahui oleh orang yang tidak berkepentingan.

b) Authenticity (autentisitas), artinya penerima pesan harus mengetahui atau mempunyai kepastian siapa pengirim pesan dan bahwa benar pesan itu dikirim oleh pengirim. Istilah ini juga berhubungan dengn suatu proses verifikasi terhadap identitas seseorang.

c) Integrity (integritas/keutuhan), artinya penerima harus merasa yakin bahwa pesan yang diterimanya tidak pernah diubah sejak pesan itu dikirim sampai diterima, seorang pengacau tidak dapat mengubah atau menukar isi pesan yang asli dengan yang palsu.

d) Non repudiation (tidak dapat disangkal), artinya pengirim pesan tidak dapat menyangkal bahwa ia tidak pernah mengirim pesan tersebut.

5. Cara Kerja AdSense

Google AdSense menyediakan cara bagi pemilik situs untuk mendapatkan uang dari konten online mereka. AdSense bekerja dengan mencocokkan iklan teks dan iklan bergambar dengan situs publisher berdasarkan konten dan pengunjung. Iklan tersebut dibuat dan dibayar oleh pengiklan yang ingin mempromosikan produk mereka. Karena para pengiklan membayar iklan yang berbeda dengan harga berbeda, maka jumlah yang Anda peroleh tidak akan sama. AdSense bekerja dengan 3 langkah berikut: 
1) Menyediakan ruang Iklan

Menyediakan ruang iklan situs dengan menempelkan kode iklan di situs dan memilih lokasi untuk menampilkan iklan.

2) Iklan yang membayar paling tinggi akan muncul di situs publisher

Pengiklan akan menawar agar ditampilkan dalam ruang iklan publisher di pelelangan waktu nyata. Iklan yang membayar paling tinggi akan ditampilkan di situs website.

3) Publisher akan di bayar

Pihak adsense menangani proses penagihan semua pengiklan dan jaringan untuk iklan di situs, guna memastikan publisher menerima pembayaran tersebut.

AdSense memiliki kebijakan untuk partisipasi yang harus dipatuhi, penayang yang memilih untuk menggunakan layanan AdSense harus mematuhi kebijakan program. Jika Anda gagal mematuhi kebijakan ini, kami akan menonaktifkan akun AdSense publisher. Dalam banyak kasus, kami lebih suka bekerja dengan penayang untuk mencapai kepatuhan kebijakan; namun, kami berhak untuk tidak menampilkan iklan yang melanggar kebijakan ini, menonaktifkan penayangan iklan pada halaman yang melanggar kebijakan ini, menahan pembayaran, atau menutup akun yang mengganggu.

Halaman Izin iklan di akun adalah tempat untuk memberi tahu pihak google adsense jika ada iklan yang tidak Anda inginkan, dan jenis iklan yang tidak Anda inginkan. Perhatikan bahwa pemblokiran iklan akan memperkecil potensi penghasilan, karena pemblokiran ini mengurangi persaingan untuk ruang iklan dengan menghilangkan bid pengiklan dari lelang. Saran untuk memblokir hanya iklan yang menurut publisher tidak cocok bagi pengguna.

Publisher dapat mencegah iklan dari URL pengiklan tertentu agar tidak ditampilkan di situs pada halaman Izin \& blokir iklan di akun AdSense Anda. Jumlah maksimum URL pengiklan yang dapat Anda blokir adalah 500 per produk AdSense. Anda dapat menerapkan 500 pemblokiran di tingkat situs atau di tingkat produk dan di setiap kombinasi yang Anda sukai hingga mencapai batas. Misalnya Anda menjalankan empat situs dan memblokir 100 URL pengiklan di setiap situs tersebut. Apabila kemudian Anda memblokir 100 URL pengiklan lagi di seluruh situs Anda, Anda akan mencapai batas 500 URL.

6. Konten Terlarang oleh pihak Adsense

1) Konten khusus dewasa

2) Tema dewasa dalam konten keluarga 


\section{Advertising Pay Per Click (PPC) Dengan Google Adsense}

3) Konten yang berbahaya atau menghina

4) Konten yang terkait dengan narkoba

5) Konten yang terkait dengan minuman beralkohol

6) Konten yang terkait dengan tembakau

7) Konten yang terkait dengan perjudian dan permainan

8) Konten hacking dan cracking halaman yang menawarkan program kompensasi

9) Konten yang menyesatkan

10) Konten yang terkait dengan senjata

7. Metode pembayaran PPC dari google adsense diantaranya adalah:

a. Melalui Western Union

Metode pembayaran Adsense yang paling umum digunakan khususnya di Indonesia yaitu dengan menggunakan western union. Jika penghasilan dalam akun adsense anda sudah mencapai $\$ 100$ atau lebih, maka pada akhir bulan nantinya akan muncul informasi pembayaran adsense yang dicairkan di western union.

Untuk mencairkan komisi adsense ini anda harus membawa informasi diatas yaitu informasi diatas yaitu informasi mengenai nomor MTCN (Money Transfer Control Number), jumlah dolar penghasilan adsense yang akan dicairkan, alamat pengirim yaitu Google Inc. Serta KTP asli dan fotocopynya.

b. Melalui transfer ke rekening bank lokal (wire transfer)

Sejak tahun 2014, google sudah mendukung pemain adsense Indonesia untuk bisa menerima bayaran penghasilan adsense lewat transfer ke rekening bank kita.

c. Melalui standard check

Cara yang kedua yaitu menggunakan cek standar. Jika anda memilih ini nantinya kalau penghasilan adsense dalam akun anda sudah mencapai payment threshold maka google akan mengirim sebuah cek ke alamat rumah anda, tempat anda menabung.

d. Check via secured express delivery

Cara yang ketiga yaitu pembayaran adsense melalui cek ekspress. Kelebihan cek ekspress dibandingkan dengan cek standar yaitu bisa sampai ke alamat anda lebih cepat dan lebih aman. Akan tetapi, ada biaya tambahan yang harus anda bayar yaitu sebesar $\$ 25$.

e. Melalaui EFT (Electronic Fund Transfer).

Yaitu merupakan cara pembayaran adsense paling cepat dan aman. Akan tetapi metode pembayaran ini belum 
tersedia di Indonesia dan hanya tersedia di beberapa negara maju saja. Dengan metode pembayaran melalui EFT ini penghasilan adsense akan dikirim langsung ke rekening pemilik akun.

\section{Prinsip Hukum Bisnis Islam}

Prinsip hukum bisnis Islam menjadi bagian terpenting dari fikih muamalat, yang mengikuti kaidah "semua hal yang terkait dengan transaksi adalah boleh, kecuali ada ketentuan nash yang melarangnya" (Asep Saepudin Jahar dkk, 2013: 229). Sumber hukum pokok dan utama dalam ekonomi syariah adalah kitab suci Al-Quran yang merupakan wahyu dari Allah SWT yang diturunkan melalui nabi Muhammad SAW, sumber yang kedua adalah al Hadist yang merupakan kumpulan setiap perkatan nabi tentang sesuatu, dan yang ketiga adalah ijma' yang merupakan kesepakatan para ulama tentang suatu hal. (Abdul R Saliman, 2015: 50)

Ada beberapa asas-asas hukum yang terkandung di dalam konsep hukum perdata Islam yang menjadi tumpuan atau landasan untuk melindungi kepentingan pribadi seseorang yaitu:

a. Asas kebolehan (Mubah)

Secara prinsip aiaslam membolehkan semua hubungan hukum muamalah selama hubungan itu tidak secara tegas dilarang oleh alQuran dan as-Sunnah

b. Asas kemaslahatan hidup

Bahwa setiap hubungan keperdataan harus senantiasa mendatangkan kebaikan dan berfaedah bagi kehidupan.

c. Asas kebebasan dan kesukarelaan

Bahwa setiap hubungan keperdataan atau muamalah harus didasarkaan kesukarelaan dan kebebasan dari paha pihak.

d. Asas menolak mudharat dan mengambil manfaat

Manfaat harus menjadi tujuan utama dan sejauh mungkin harus dihindari adanya mudharat, yaitu sesuatu yang mendatangkan kerugian bagi para pihak.

e. Asas kebijakan atau kebaikan

Setiap hubungan harus mendatangkan kebaikan bagi para pihak, termasuk pihak ketiga atau masyarakat sekitar.

f. Asas kekeluargaan 


\section{Advertising Pay Per Click (PPC) Dengan Google Adsense}

Asas kekeluargaan atau kebersamaan adalah asas yang disandarkan pada pada hormat menghormati dan tolong menolong dalam mencapai tujuan bersama.

a) Al Hurriyah (kebebasan)

Asas ini merupakan prinsip dasar dalam hukum perjanjian

Islam, dalam artian, para pihak bebas membuat suatu perjanjian atau suatu akad.

b) Al. Musawah (persamaan atau kesetaraan)

Asas ini mengandung pengertian bahwa para pihak mempunyai kedudukan yang sama, sehingga dalam menentukan term and condition dari suatu akad atau perjanjian dari suatu pihak mempunyai kedudukan yang seimbang

c) Al adalah (keadilan)

Pelaksanaan asas ini dalam suatu perjanjian menurut para pihak untuk melaksanakan yang benar dalam mengungkapkan kehendak dan keadaan, memenuhi semua kewajibannya.

d) Al Ridha (kerelaan)

Asas ini menyatakan bahwa transaksi yang dilakukan atas dasar kerelaan dari masing-masing pihak, tidak boleh ada unsur paksaan, tekanan, dan penipuan.

e) Ash Shidq (kebenaran)

Dalam Islam semua orang dilakukan melakukan kebohongan dan penipuan, karena penipuan sangat berpengaruh pada keabsahan perjanjian.

f) Al kitabah (tertulis)

Setiap perjanjian hendaknya dibuat secara tertulis, berkaitan demi kepentingan pembuktian jika dikemudian hari terjadi sengketa.( Abdul Ghafur Anshori, 2010: 34)

\section{Advertising PPC dengan Google Adsense Perspektif Hukum Islam}

Advertising atau periklanan adalah komunikasi komersil dan nonpersonal tentang sebuah organisasi dan produk-produknya yang ditransmisikan ke suatu khalayak target melalui media bersifat massal, seperti televisi, radio, koran, majalah, internet, direct mail, dan lainlain.( Monle lee dan Carla Johnson, 2011:3)

Sistem Advertising atau periklanan dijadikan media untuk usaha atau bisnis $e$ commerce. Orang yang terjun ke dunia usaha, berkewajiban mengetahui hal-hal yang dapat mengakibatkan jual beli itu sah atau fasid. Ini dimaksudkan agar mu'amalah berjalan sah dan segala sikap dan tindakannya jauh dari kerusakan yang tidak dibenarkan. Transaksi (akad) merupakan unsur penting dalam suatu 


\section{Dika Saputri}

perikatan. Dalam Islam persoalan transaksi sangat tegas dalam penerapannya, dan ini membuktikan bahwa keberadaan transaksi tidak boleh dikesampingkan begitu saja dalam setiap bidang kehidupan manusia (umat Islam).

Pelaksanaan transaksi bisnis Pay per Click, secara sekilas hampir serupa dengan syirkah atau kerjasama, karena didalam PPC oleh google adsense, terdapat kebijakan-kebijakan atau perjanjian yang harus disepakati oleh kedua belah pihak. apabila salah satu peraturan dilanggar, maka gugur oleh google adsense. Meskipun program adsense akan memberikan keuntungan besar, google telah menetapkan aturan ketat untuk melindungi kepentingan semua pihak yang terlibat di dalamnya, termasuk kepada pemasang iklan yang sering dirugikan oleh tindakan tidak terpuji pemilik situs anggota program adsense (Team Cyber, 2009:63).

Pada dasarnya, program PPC merupakan sebuah cara bagi perusahaan untuk meningkatkan jumlah pengunjung ke website mereka. Hal ini dilakukan sebagai salah satu bentuk promosi terhadap produk atau jasa yang mereka tawarkan. Namun, pada perkembangannya program PPC tidak hanya bersifat promosi terhadap produk atau jasa, tetapi juga menawarkan seseorang untuk mendapatkan penghasilan tambahan dengan cepat dan mudah.

Transaksi atau akad merupakan unsur paling penting dalam suatu perikatan. Dalam Islam, persoalan transaksi sangat tegas dalam penerapannya dan ini membuktikan bahwa keberadaan transaksi tidak boleh dikesampingkan begitu saja dalam setiap bidang kehidupan manusia (umat Islam) karena begitu pentingnya transaksi dalam suatu perjanjian. Dalam transaksi e commerce melalui internet perintah pembayaran (payment intruction) melibatkan beberapa pihak selain cardholder dan merchant. Para pihak itu adalah payment, gateway, acquairer dan issuer. Dalam transaksi online merupakan suatu keharusan adanya pihak-pihak lain yang terlibat.

Sesuai dengan keterangan diatas, penulis sependapat dengan Syekh Muhammad Shalih al Munajjid bahwa pada asalnya, tidak boleh bergabung dalam google adsense kecuali setelah memastikan bersihnya berbagai situs yang diiklankan dari hal-hal yang haram, karena tidaklah diperbolehkan mengumumkan, mengiklankan, dan membantu untuk menyebarkan kemungkaran. Allah berfirman dalam surat al-maidah ayat : 2 


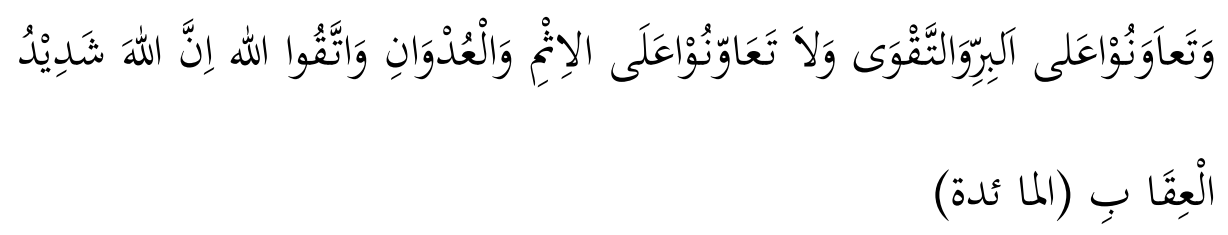

Artinya: "Dan saling tolong menolonglah dalam kebaikan dan takwa dan janganlah tolong menolong dalam dosa dan tindakan kelewat batas. Dan bertaqwalah kepada allah. Sesungguhnya"

Nabi Muhammad SAW bersabda, Siapa saja yang mengajak kepada hidayah maka dia akan mendapatkan pahala semisal pahala yang didapatkan oleh orang-orang yang mengikutinya tanpa mengurangi pahala mereka sedikit pun. Sebaliknya, siapa saja yang mengajak kepada kesesatan maka dia akan menanggung dosa semisal dosa orang-orang yang mengikutinya tanpa mengurangi dosa mereka sedikit pun. (HR. Muslim)

Jika memang realitanya sebagaimana yang dikatakan bahwa mayoritas situs yang diiklankan di situs adsense adalah situs-situs mengenai pengajaran berbagai bahasa atau semisal dengan itu maka tidaklah mengapa jika seseorang tergabung dalam Google Adsense. Terlebih lagi, jika memang sangat membutuhkan penghasilan.

Ada kewajiban untuk tidak mengiklankan situs-situs yang bertentangan dengan hukum syariat. Jika tidak mampu melakukan hal ini-dengan kata lain, situs-situs terlarang tersebut tetap muncul di situs, maka wajib untuk meninggalkan bisnis jual jasa ini karena jika tidak mundur dari bisnis ini, seorang Publisher akan menjadi orang yang berperan serta menyebarluaskan dan mengiklankan hal yang hukumnya haram.

Tetapi sebaliknya, jika sistem advertising dari PPC ini digunakan dalam hal yang baik dan dijalan yang benar, memberi manfaat terhadap orang lain, maka diperbolehkan membuat bisnis dari PPC oleh google adsense tersebut. Dalam kaidah fiqhiyah disebutkan :

$$
\text { الاصل فى المعا ملة الابا حة الا ان يدل دليل على تحريمها }
$$

Artinya : "Hukum asal dari bentuk muamalah adalah boleh, kecuali ada dalil yang melarangnya"

Setiap transaksi, pada dasarnya boleh, seperti ijarah, syirkah, dan transaksi lainnya. kaidah ini juga berlaku bagi transaksi kontemporer yang ketentuannya tidak dijelaskan dalam al-qur'an dan hadist : 


$$
\text { الأصل فى العقد رضي العتعاقدين ونتيجته ما التزماه بالتعاقد }
$$

Artinya : "Hukum asal dari sebuah transaksi pada keredaan dari kedua belah pihak dan apabila kedua belah pihak rela, maka akad menjadi sah."

Salah satu prinsip transaksi dalam Islam adalah kerelaan kedua belah pihak, apabila salah satu pihak tidak meridhoinya, transaksi menjadi batal (Farida Arianti, 2016:147).

Menurut analisa penulis, sistem Pay Per Click ini harus didaftarkan kepada google adsense yang mana terdapat peraturan dan kebijakan dari pihak google yang harus disetujui oleh seorang publisher. jika seorang sudah terdaftar dalam adsense, artinya telah menyetujui dan di anggap kedua belah pihak setuju.

\section{Kesimpulan}

Dapat disimpulkan bahwa Program yang menghasilkan uang adalah google adsense. Adsense adalah program legal yang dibuat oleh google yang telah memiliki nama besar di dunia maya sebagai situs pencari yang terkenal. Program affiliasi untuk bisnis internet yang sangat populer di dunia online saat ini adalah google adsense. Semua orang bisa berpartisipasi menjadi pengiklan bagi Google dengan syarat mudah dan cepat, cukup dengan menempatkan iklan-iklan Google di situs mereka. Dengan metode komisi Pay Per Click (PPC).

Metode pembayaran Adsense yang paling umum digunakan khususnya di Indonesia yaitu dengan menggunakan western union. Jika penghasilan dalam akun adsense sudah mencapai $\$ 100$ atau lebih, maka pada akhir bulan nantinya akan muncul informasi pembayaran adsense yang dicairkan di western union. selsin Western Unioin, cara yang kedua yaitu menggunakan cek standar. Jika publisher memilih ini nantinya kalau penghasilan adsense dalam akun sudah mencapai payment threshold maka google akan mengirim sebuah cek ke alamat rumah, tempat publisher menabung.

Mekanisme Transaksi dan akad yang digunakan dalam Google Adsense serta melihat unsur-unsur kontrak yang ada di dalamnya, maka prinsip-prinsip syariah masih dapat diberlakukan. Salah satu prinsip transaksi dalam Islam adalah kerelaan kedua belah pihak, apabila salah satu pihak tidak meridhoinya, transaksi menjadi batal. Dalam analisa penulis, sistem Pay Per Click ini harus di daftarkan kepada google adsense yang mana terdapat peraturan dan kebijakan dari pihak google yang harus disetujui oleh seorang publisher. jika seorang sudah terdaftar dalam adsense, artinya telah menyetujui dan di anggap kedua belah pihak setuju. 


\section{DAFTAR PUSTAKA}

Abdul R Saliman, Hukum Bisnis Untuk Perusahaan Teori dan Contoh Kasus, Kencana, 2015, Jakarta.

Abdul Ghofur Anshori, Hukum Perjanjian Islam di Indonesia, Gajah Mada University Press, 2010, Yogyakarta.

Adi Nugroho, E-Commerce-Memahami Perdagangan,modern di dunia maya, informatika, 2008.

Asep saepudin jahar dkk, Hukum Keluarga, Pidana, dan Bisnis kajian Perundang-undangan Indonesia, Fikih dan Hukum Internasional, Kencana Prenadamedia group, 2013, Jakarta.

Dwi Suwiknyo, Bisnis Online Syari'ah, Trust Media, 2009, Yogyakarta.

Farida Arianti, Transaksi Terlarang dalam Hukum Ekonomi Islam, STAIN Batu Sangkar Press, 2016, Yogyakarta.

Hurriyah Badriyah, Rahasia Sukses Besar Bisnis Online tanpa Modal, Redaksi Kunci Komunikasi, 2014, Jakarta.

Monle lee dan Carla Johnson, Prinsip-prinsip Pokok Periklanan dalam Perspektif Global, Kencana, 2011, Jakarta.

Richardus Eko Indrajit, E-Commerce; Kiat dan Strategi Bisnis di Diunia Maya, PT Elex Komputindo, 2001, Jakarata.

Riyeke Ustadiyanto, Framework E-Commerce, Andi Offset, 2001, Yokyakarta.

Team Cyber, Mengeruk Dollar dari Internet Google Adsense, Cyber Community, 2009, Jakarta.

Vilency, satriamaya community, The Power of Google, CV Andi Offset, 2010, Yogyakarta. 

